\title{
Association Between Serum 25-Hydroxyvitamin D Concentrations and Chronic Pain: Effects of Drinking Habits
}

This article was published in the following Dove Press journal: Journal of Pain Research

Keita Suzuki, (D' Hiromasa Tsujiguchi, ${ }^{\text {I-3 }}$ Sakae Miyagi, (D) ${ }^{3,4}$ Thao Thi Thu Nguyen, ${ }^{2}$ Akinori Hara, ${ }^{\text {I-3 }}$ Haruki Nakamura, ${ }^{2}$ Yukari Shimizu, ${ }^{5}$ Koichiro Hayashi,' Yohei Yamada,' Phat Minh Nguyen, (D) ${ }^{2}$ Yuichi Tao, ${ }^{2}$ Takayuki Kannon, (D) ${ }^{3,6}$ Atsushi Tajima, $\mathbb{D}^{3,6}$ Hiroyuki Nakamura $^{\text {I-3 }}$

'Department of Public Health, Graduate School of Advanced Preventive Medical Sciences, Kanazawa University, Kanazawa, Ishikawa 920-8640, Japan; ${ }^{2}$ Department of Environmental and Preventive Medicine, Graduate School of Medical Science, Kanazawa University, Kanazawa, Ishikawa 920-8640, Japan; ${ }^{3}$ Kanazawa University Advanced Preventive Medical Sciences Research Center, Kanazawa, Ishikawa 920-8640, Japan; ${ }^{4}$ Innovative Clinical Research Center, Kanazawa University, Kanazawa, Ishikawa 920-8640, Japan; ${ }^{5}$ Department of Nursing, Faculty of Health Sciences, Komatsu University, Komatsu, Ishikawa 923-096I, Japan; ${ }^{6}$ Department of Bioinformatics and Genomics, Graduate School of Advanced Preventive Medical Sciences, Kanazawa University, Kanazawa, Ishikawa 920-8640, Japan
Correspondence: Keita Suzuki Department of Public Health, Graduate School of Advanced Preventive Medical Sciences, Kanazawa University, I3-I,

Takara-Machi, Kanazawa, Ishikawa 9208640, Japan

Tel +8I-76-265-2218

Fax +8I-76-234-4233

Email keitasuzuk@stu.kanazawa-u.ac.jp
Purpose: Although the explanation for inconsistencies in the reported association between serum 25-hydroxyvitamin D [25(OH)D] levels and chronic pain (CP) has not yet been determined, understanding this discrepancy is necessary for the development of vitamin $\mathrm{D}$ supplementation as an effective treatment for CP. The aim of this cross-sectional study was to examine the relationship between $25(\mathrm{OH}) \mathrm{D}$ concentrations and $\mathrm{CP}$ according to drinking habits in Japanese subjects.

Patients and Methods: We distributed invitation letters to 2314 individuals older than 40 years in Shika town, a rural area in Japan, and 724 subjects (386 females; mean age: $63.9 \pm$ 10.4 years) were recruited. CP was defined as persistent pain lasting at least 3 months in any part of the body. Serum concentrations of $25(\mathrm{OH}) \mathrm{D}$, a biomarker of the vitamin $\mathrm{D}$ status, were measured using a radioimmunoassay. A serum 25(OH)D level $<20 \mathrm{ng} / \mathrm{mL}$ was defined as serum $25(\mathrm{OH}) \mathrm{D}$ deficiency. Drinking habits were assessed using a self-administered questionnaire. There were three choices, "rarely drink", "sometimes" and "everyday". Respondents who answered "rarely drink" were labelled as non-drinkers and the others as drinkers.

Results: The prevalence of CP was $40.6 \%$. A significant interaction between $\mathrm{CP}$ and drinking habits on $25(\mathrm{OH}) \mathrm{D}$ concentrations was observed $(p=0.098)$. A one-way analysis of covariance was performed to compare $25(\mathrm{OH}) \mathrm{D}$ concentrations between the subjects with and without $\mathrm{CP}$ in each drinking group, and the serum $25(\mathrm{OH}) \mathrm{D}$ levels of subjects with $\mathrm{CP}$ were significantly lower than those without CP among drinkers $(p=0.007)$. A logistic regression analysis revealed a correlation between serum $25(\mathrm{OH}) \mathrm{D}$ deficiency and $\mathrm{CP}$ in drinkers after adjustments for several confounding factors (odds ratio: $0.499 ; 95 \%$ confidence interval: $0.268-0.927 ; p=0.028$ ).

Conclusion: The present results suggest that low serum $25(\mathrm{OH}) \mathrm{D}$ concentrations are associated with the development of CP in drinkers.

Keywords: pain, vitamin D, alcohol, cross-sectional analysis, epidemiology

\section{Introduction}

The International Association for the Study of Pain (IASP) defines chronic pain (CP) as pain without an apparent biological cause that persists for longer than 3 months. ${ }^{1}$ A meta-analysis from the United Kingdom reported that the prevalence of CP ranged from $35.0 \%$ to $51.3 \% .^{2}$ Another review reported that $25 \%-76 \%$ of older people living in the community had $\mathrm{CP}^{3} \mathrm{CP}$ has a negative impact on health-related quality of life, work productivity and increases the risk of developing depression and anxiety. ${ }^{4}$ Furthermore, the national cost of pain in the United States in 2008 
was estimated to be between 560 and 635 billion dollars. ${ }^{5}$ Therefore, the development of effective and reasonable treatments is urgently needed.

Vitamin D is a vital hormone for optimal neuromuscular, bone, and immune functions, and its sources are dietary intake and cutaneous synthesis. Vitamin D is metabolized into 25-hydroxyvitamin D [25(OH)D] in the liver and then into 1,25-dihydroxyvitamin $\mathrm{D}[1,25(\mathrm{OH})$ 2D] in the kidneys. ${ }^{6}$ Serum $25(\mathrm{OH}) \mathrm{D}$ concentrations are regarded as the most useful marker of the vitamin D status stored from sunlight exposure, dietary intake, supplements, and other factors. ${ }^{7}$

Interventional studies previously reported the efficacy of vitamin D supplementation for the treatment of CP as well as good patient adherence. ${ }^{8-10}$ However, the 2015 Cochrane review concluded that vitamin $\mathrm{D}$ was not significantly beneficial for various $\mathrm{CP}$ conditions. ${ }^{11}$ Although observational studies examined the relationship between $25(\mathrm{OH}) \mathrm{D}$ concentrations and $\mathrm{CP}$, the findings obtained have been inconsistent. ${ }^{12-14}$ The reasons for these disparities have not yet been identified, but need to be clarified for the development of vitamin D supplementation as an effective treatment for CP.

Several previous studies have reported that alcohol consumption is associated with a reduced risk of vitamin D deficiency, ${ }^{15,16}$ whereas other studies have reported a negative association $^{17-19}$ or no association. $^{20-22}$ Although alcohol has been shown to influence the expression of the parathyroid hormone ${ }^{23-25}$ or CYP24A1 induction $^{26}$ in several studies, the mechanism underlying the association between alcohol and serum 25(OH)D levels remains unknown. However, one possibility is that alcohol consumption may affect $\mathrm{CP}$ by modulating the vitamin D status. Therefore, performing a subgroup analysis stratified by drinking habits is necessary to clearly evaluate the association between $\mathrm{CP}$ and serum 25(OH)D concentrations.

Based on these studies, we hypothesized that alcohol consumption may affect the association between $\mathrm{CP}$ and 25 $(\mathrm{OH}) \mathrm{D}$ concentrations. Therefore, we herein investigated the association between $\mathrm{CP}$ and serum 25(OH)D concentrations among individuals who do and do not consume alcohol.

\section{Materials and Methods}

\section{Study Design and Subjects}

We utilized cross-sectional data gathered between 2011 and 2015 in the Shika study. The Shika study is a longitudinal community-based observational study that has been conducted among the residents of Shika town, located on Noto peninsula in Ishikawa prefecture, since 2011. The town has more than 20,000 residents, and the climate is humid subtropical. We recruited subjects from two model districts in the town for the present study. We invited all adults older than 40 years $(n=2314)$ in the districts to participate. A self-administrated questionnaire was delivered to all subjects by trained interviewers, who explained the outline of the Shika study and how to fill in the questionnaire. In total, 2199 subjects $(95 \%)$ responded to the questionnaire, and 972 (42\%) who underwent a comprehensive health examination were included.

We omitted subjects with data missing on the variables used in the analysis. To avoid a treatment bias, we also excluded subjects who had been using vitamin D supplementation. Therefore, data collected from 724 subjects who completed the health examination and replied to the questionnaire were available for analysis in the present study. The details of recruitment are shown in Figure 1.

The present study was conducted with the approval of the Ethics Committee of Kanazawa University (No.1491). All subjects provided written informed consent for inclusion before they participated in the present study. The study was conducted in accordance with the Declaration of Helsinki.

\section{Pain Questions}

We asked subjects "Have you been having any pain persisting for 3 months or longer?" on a self-administered questionnaire. The definition of $\mathrm{CP}$ was according to that presented by IASP. ${ }^{1}$ Subjects with CP were assigned to the CP group.

\section{Serum 25(OH)D Measurement}

Fasting blood samples were collected from all subjects at the health examination. Serum $25(\mathrm{OH}) \mathrm{D}$ concentrations were measured using a radioimmunoassay (RIA) (25hydroxyvitamin D 125I RIA Kit, DiaSorin Inc., Stillwater, Minnesota, USA). Coefficients of variation for inter-assay of high-performance liquid chromatography (HPLC), competitive protein binding, and RIA, have been reported to be $8.4 \%, 14 \%$, and $<12 \%$, respectively. ${ }^{27}$ A previous study that measured serum 25 $(\mathrm{OH}) \mathrm{D}$ levels using HPLC-atmospheric pressure chemical ionization-mass spectrometry, RIA, and chemiluminescent immunoassays reported that the RIA value was between that of the other two techniques. ${ }^{28}$ 


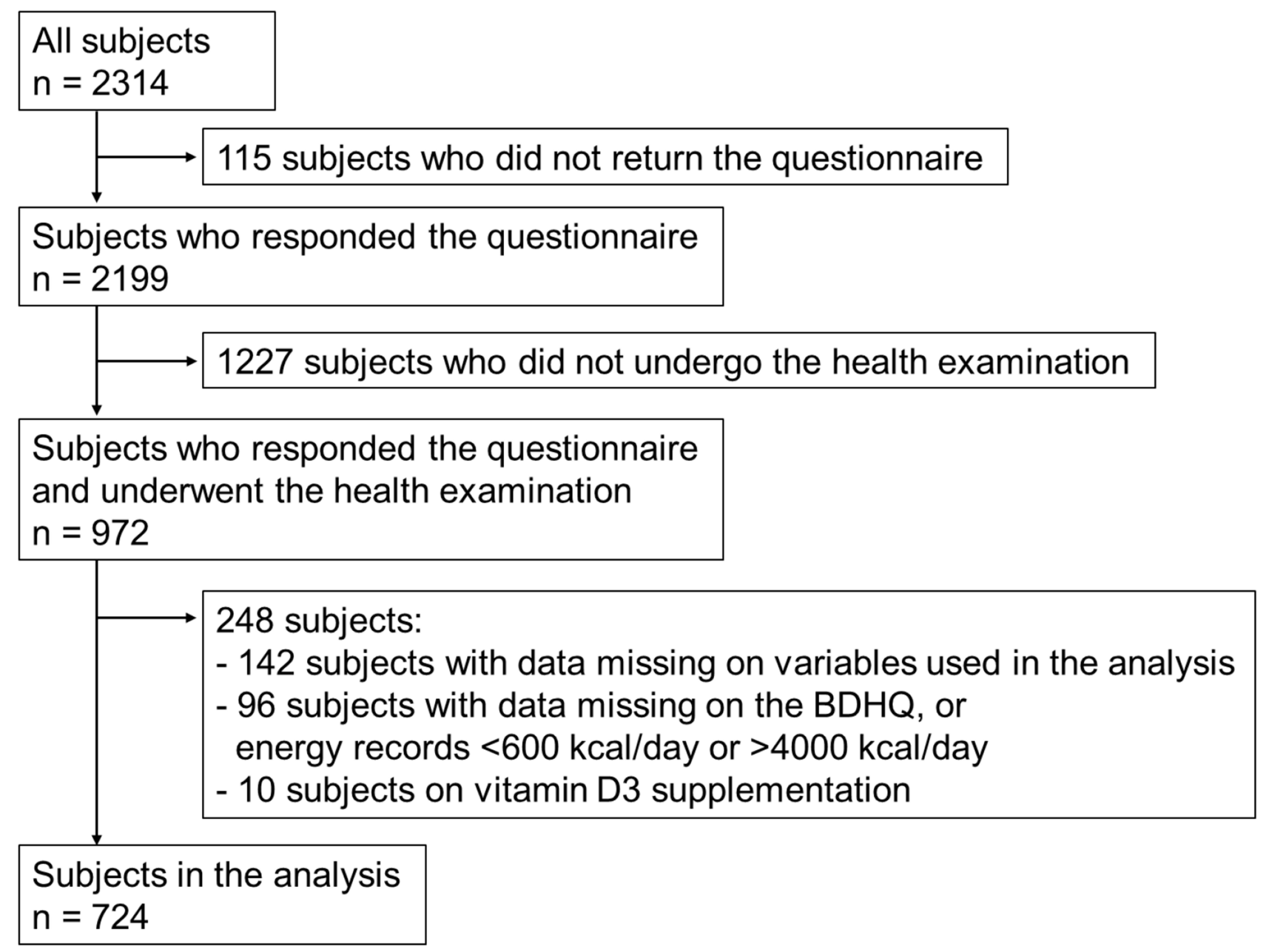

Figure I Flow chart of subject recruitment.

According to several previous reports, the minimum desirable serum $25(\mathrm{OH}) \mathrm{D}$ level is $20 \mathrm{ng} / \mathrm{mL}$ $(50 \mathrm{nmol} / \mathrm{L}) \cdot{ }^{29,30}$ Therefore, a serum $25(\mathrm{OH}) \mathrm{D}$ level $<20 \mathrm{ng} / \mathrm{mL}$ was defined as serum 25(OH)D deficiency in this study.

\section{Questions on Drinking Habits}

The drinking habits of the participant were collected by questionnaire. We used a structured-question to ask if the participants drink alcohol or not. The participant was asked, "How often do you drink alcohol?" There were three choices, "rarely drink", "sometimes" and "everyday". We assigned subjects who answered "rarely drink" as "non-drinkers", and the others as "drinkers" for the analysis.

\section{Other Variables}

We measured age, height, weight, grip strength, calf circumference, $\mathrm{C}$-reactive protein (CRP), and the osteo sono- assessment index in all subjects at the health examination. Body mass index (BMI) was calculated as weight in kilograms divided by the square of height in meters. The values of grip strength and calf circumference were divided by body weight to adjust for the influence of physique, and these values were used in the analysis.

To assess the smoking status and frequency of exercise, we used self-administered questionnaires. Subjects were classified into the following three groups according to their smoking status: the non-smoker group, the ex-smoker group, and the current smoker group. We also assigned subjects into three groups according to the frequency of walking for more than $30 \mathrm{~min}$ in 1 week as follows: more than 5 days, 1 to 4 days, and no exercise. The analgesics administration status was also assessed on the selfadministered questionnaire.

We evaluated the nutritional status using a brief-type self-administered diet history questionnaire (BDHQ) that 
asked subjects about the consumption frequency of 58 food and beverage items during the previous month. These items are mainly from the food list used in the National Health and Nutrition Survey of Japan and commonly consumed in Japan. The validity of BDHQ has been demonstrated in other studies, and is considered to have a satisfactory ranking ability for many nutrients in Japanese subjects. $^{31,32}$ We excluded all subjects who reported a total energy intake of less than $600 \mathrm{kcal} /$ day (half of the energy intake required for the lowest physical activity category) or more than $4000 \mathrm{kcal} / \mathrm{day}$ (1.5-fold the energy intake required for the moderate physical activity category) to avoid under/overestimations leading to bias in the analysis of other nutrients. We obtained data on total energy, protein, lipid, carbohydrate, and vitamin D intake, and nutrient data were adjusted for daily energy intake using the density method.

\section{Statistical Analysis}

We summarized continuous variables as means and standard deviation (SD), and presented categorical variables as numbers (N) and percentages (\%). To compare differences in the mean levels of continuous variables and categorical variables between subjects with and without $\mathrm{CP}$ in each drinking group, the Student's $t$-test and chi-squared test were used. A twoway analysis of covariance (ANCOVA) was performed to assess the interaction on serum $25(\mathrm{OH}) \mathrm{D}$ concentrations between the $\mathrm{CP}$ status and drinking habits with adjustments for sex, age, BMI, the smoking status, exercise habit, the analgesics administration status, the osteo sono-assessment index, grip strength/body weight, and calf circumference/body weight. To confirm differences in the adjusted serum $25(\mathrm{OH}) \mathrm{D}$ concentrations between the subjects with and without $\mathrm{CP}$ in each drinking habits group, we used a one-way ANCOVA with adjustments for sex, age, BMI, the smoking status, exercise habit, the analgesics administration status, the osteo sono-assessment index, grip strength/body weight, and calf circumference/body weight. The Bonferroni post hoc test was then conducted for multiple comparisons. A multiple logistic regression analysis was performed to examine the association between $\mathrm{CP}$ and the categorized 25(OH)D levels in each drinking group after adjustments for the following independent factors: sex, age, BMI, the smoking status, exercise habit, the analgesics administration status, the osteo sono-assessment index, grip strength/body weight, and calf circumference/body weight.

We performed all statistical analyses using IBM SPSS Statistics version 21.0 (SPSS Inc., Armonk, NY, USA). A two-sided $p$-value $<0.05$ was considered to be significant. A $p$-value $<0.10$ was considered significant for the interaction test.

\section{Results}

\section{Subject Characteristics}

Table 1 shows the characteristics of subjects according to CP. The mean age of the 724 subjects analyzed in the present study was $63.9 \pm 10.4$ years. A total of 294 (40.6\%) subjects had CP. Mean serum 25(OH)D concentrations in the groups with and without CP were $24.37 \pm$ 8.25 and $23.58 \pm 7.36 \mathrm{ng} / \mathrm{mL}$, respectively. In total, $43.3 \%$ of non-CP subjects and $50.7 \%$ of $\mathrm{CP}$ subjects were drinkers.

\section{Subject Characteristics According to $\mathrm{CP}$ and Drinking Habits}

Table 2 shows the subject characteristics according to $\mathrm{CP}$ and drinking habits. In non-drinkers, no significant differences were observed in $25(\mathrm{OH}) \mathrm{D}$ concentrations between the groups with and without $\mathrm{CP}$, whereas among drinkers, a slight difference was noted between these groups $(p=0.072)$. Among non-drinkers, significant differences were found in grip strength/body weight $(p=0.002)$ and the osteo sono-assessment index ( $p=$ 0.011) between the groups with and without CP. Drinkers with CP had significantly lower protein ( $p=$ $0.014)$ and vitamin $\mathrm{D}$ intakes $(p=0.009)$ than those without CP.

\section{Interaction Between CP and Drinking Habits on Serum 25(OH)D Concentrations and Comparison of Adjusted Serum 25(OH)D Values}

A two-way ANCOVA was performed to examine the interaction between $\mathrm{CP}$ and drinking habits on serum 25(OH)D concentrations (Table 3). We observed a significant main effect of CP $(p=0.021)$ and drinking habits $(p<0.001)$. A significant interaction was noted between $\mathrm{CP}$ and drinking habits on serum 25(OH)D levels after adjustments for covariates $(p=0.098)$. The one-way ANCOVA revealed that the subjects without 
Table I Subject Characteristics

\begin{tabular}{|c|c|c|c|c|c|c|c|}
\hline & \multicolumn{2}{|l|}{ Total } & \multicolumn{2}{|c|}{ Without CP } & \multicolumn{2}{|l|}{ With CP } & \multirow[t]{2}{*}{$p$-value } \\
\hline & Mean (n) & SD (\%) & Mean (n) & SD (\%) & Mean (n) & SD (\%) & \\
\hline Male (n, \%) & 338 & 46.7 & 194 & 45.1 & 144 & 49.0 & 0.306 \\
\hline Age (years) & 63.9 & 10.4 & 63.3 & 10.0 & 64.7 & 10.8 & 0.072 \\
\hline Height (cm) & 159.1 & 9.4 & 158.9 & 8.8 & 159.4 & 10.3 & 0.538 \\
\hline Weight (kg) & 59.2 & 11.0 & 59.0 & II.I & 59.5 & 10.9 & 0.617 \\
\hline BMI $\left(\mathrm{kg} / \mathrm{m}^{2}\right)$ & 23.3 & 3.2 & 23.3 & 3.3 & 23.3 & 3.2 & 0.845 \\
\hline $\mathrm{CRP}(\mathrm{mg} / \mathrm{dL})$ & 0.15 & 0.57 & 0.12 & 0.45 & 0.18 & 0.71 & 0.160 \\
\hline Serum $25(\mathrm{OH}) \mathrm{D}(\mathrm{ng} / \mathrm{mL})$ & 24.05 & 7.90 & 24.37 & 8.25 & 23.58 & 7.36 & 0.189 \\
\hline Total energy intake (kcal) & 1902.7 & 581.1 & 1869.7 & 553.1 & 1950.9 & 617.7 & 0.065 \\
\hline Protein intake (g//000kcal) & 14.83 & 3.12 & 15.04 & 3.15 & 14.53 & 3.06 & 0.029 \\
\hline Lipid intake (g/l000kcal) & 23.52 & 5.87 & 23.72 & 5.61 & 23.23 & 6.23 & 0.266 \\
\hline Carbohydrate intake (g/1000kcal) & 55.53 & 8.29 & 55.42 & 8.44 & 55.68 & 8.06 & 0.684 \\
\hline Vitamin $D$ intake $(\mu \mathrm{g} / 1000 \mathrm{kcal})$ & 7.94 & 5.15 & 8.25 & 5.37 & 7.49 & 4.78 & 0.051 \\
\hline Grip strength/body weight (kgf/kg) & 0.53 & 0.12 & 0.54 & 0.12 & 0.52 & 0.12 & 0.109 \\
\hline Calf circumference/body weight $(\mathrm{cm} / \mathrm{kg})$ & 0.58 & 0.07 & 0.58 & 0.07 & 0.58 & 0.07 & 0.288 \\
\hline Osteo sono-assessment index & 2.61 & 0.36 & 2.62 & 0.36 & 2.60 & 0.36 & 0.642 \\
\hline Smoking status (n, \%) & & & & & & & 0.842 \\
\hline Non-smoker & 384 & 53.0 & 231 & 53.7 & 153 & 52.0 & \\
\hline Ex-smoker & 213 & 29.4 & 123 & 28.6 & 90 & 30.6 & \\
\hline Current smoker & 127 & 17.5 & 76 & 17.7 & 51 & 17.3 & \\
\hline Exercise habits (n, \%) & & & & & & & 0.002 \\
\hline More than 5 days/week & 241 & 33.3 & 162 & 37.7 & 79 & 26.9 & \\
\hline I-4 days/week & 145 & 20.0 & 89 & 20.7 & 56 & 19.0 & \\
\hline No exercise & 338 & 46.7 & 179 & 41.6 & 159 & 54.1 & \\
\hline Analgesics administration (n, \%) & & & & & & & 0.010 \\
\hline No & 688 & 95.0 & 416 & 96.7 & 272 & 92.5 & \\
\hline Yes & 36 & 5.0 & 14 & 3.3 & 22 & 7.5 & \\
\hline Drinking habits (n, \%) & & & & & & & 0.049 \\
\hline Non-drinker & 389 & 53.7 & 244 & 56.7 & 145 & 49.3 & \\
\hline Drinker & 335 & 46.3 & 186 & 43.3 & 149 & 50.7 & \\
\hline
\end{tabular}

Notes: $p$-values were from the Student's $t$-test for continuous variables and the chi-squared test for categorical variables; $p$-values $<0.05$ are in bold; Total, $n=724$; Without $\mathrm{CP}, \mathrm{n}=430$; With CP, $\mathrm{n}=294$.

Abbreviations: BMI, body mass index; CRP, C-reactive protein; 25(OH)D, 25-hydroxy vitamin D; CP, chronic pain; SD, standard deviation.

$\mathrm{CP}$ had higher 25(OH)D concentrations than those with CP $(p=0.007)$ in drinkers after adjustments for covariates (Table 3 ). In non-drinkers, no significant differences were found.

\section{Association Between CP and Drinking Habits}

The association between $\mathrm{CP}$ and drinking habits is shown in Table 4. Drinking habits correlated with $\mathrm{CP}$ after adjustments for sex, age, BMI, the smoking status, exercise habit, the analgesics administration status, the osteo sonoassessment index, grip strength/body weight, and calf circumference/body weight (odds ratio: $1.467 ; 95 \%$ confidence interval: $1.018-2.114 ; p=0.040$ ).

\section{Association Between CP and Serum 25 $(\mathrm{OH}) \mathrm{D}$ Deficiency}

The association between $\mathrm{CP}$ and serum 25(OH)D deficiency in each group stratified by drinking habits are shown in Table 5. The results obtained showed that serum 25(OH)D deficiency correlated with $\mathrm{CP}$ in drinkers after adjustments for sex, age, BMI, the smoking status, exercise habit, the analgesics administration status, the osteo sono-assessment index, grip strength/body weight, and calf circumference/ 
Table 2 Comparison of Characteristics Between CP and Non-CP Subjects According to Drinking Habits

\begin{tabular}{|c|c|c|c|c|c|c|c|c|c|c|}
\hline & \multicolumn{4}{|c|}{ Non-Drinker } & \multirow[t]{3}{*}{$p$-value } & \multicolumn{4}{|c|}{ Drinker } & \multirow[t]{3}{*}{$p$-value } \\
\hline & \multicolumn{2}{|c|}{ Without CP } & \multicolumn{2}{|c|}{ With CP } & & \multicolumn{2}{|c|}{ Without CP } & \multicolumn{2}{|c|}{ With CP } & \\
\hline & $\begin{array}{l}\text { Mean } \\
(n)\end{array}$ & $\begin{array}{l}\text { SD } \\
\text { (\%) }\end{array}$ & $\begin{array}{l}\text { Mean } \\
\text { (n) }\end{array}$ & $\begin{array}{l}\text { SD } \\
\text { (\%) }\end{array}$ & & $\begin{array}{l}\text { Mean } \\
\text { (n) }\end{array}$ & $\begin{array}{l}\text { SD } \\
\text { (\%) }\end{array}$ & $\begin{array}{l}\text { Mean } \\
\text { (n) }\end{array}$ & $\begin{array}{l}\text { SD } \\
\text { (\%) }\end{array}$ & \\
\hline Male (n, \%) & 64 & 26.2 & 27 & 18.6 & 0.087 & 130 & 69.9 & 117 & 78.5 & 0.074 \\
\hline Age (years) & 64.5 & 10.3 & 66.2 & 10.5 & 0.109 & 61.8 & 9.4 & 63.3 & 11.0 & 0.188 \\
\hline Height $(\mathrm{cm})$ & 155.5 & 8.2 & 153.8 & 8.7 & 0.053 & 163.3 & 7.4 & 164.8 & 8.8 & 0.112 \\
\hline Weight (kg) & 56.3 & 10.4 & 55.3 & 9.9 & 0.340 & 62.6 & 11.0 & 63.5 & 10.3 & 0.444 \\
\hline BMI $\left(\mathrm{kg} / \mathrm{m}^{2}\right)$ & 23.2 & 3.3 & 23.3 & 3.5 & 0.737 & 23.4 & 3.2 & 23.3 & 2.8 & 0.891 \\
\hline CRP (mg/dL) & 0.10 & 0.19 & 0.25 & 0.91 & 0.050 & 0.15 & 0.65 & 0.12 & 0.44 & 0.687 \\
\hline Serum $25(\mathrm{OH}) D(\mathrm{ng} / \mathrm{mL})$ & 22.35 & 6.77 & 21.82 & 6.40 & 0.445 & 27.01 & 9.24 & 25.30 & 7.83 & 0.072 \\
\hline Total energy intake (kcal) & 1759.8 & 526.1 & 1829.7 & 597.1 & 0.229 & 2014.0 & 555.8 & 2068.8 & 616.5 & 0.394 \\
\hline Protein intake (g/l000kcal) & 15.25 & 3.05 & 15.19 & 2.68 & 0.840 & 14.78 & 3.26 & 13.89 & 3.27 & 0.014 \\
\hline Lipid intake (g//000kcal) & 24.43 & 5.43 & 24.64 & 5.66 & 0.720 & 22.79 & 5.72 & 21.86 & 6.46 & 0.161 \\
\hline Carbohydrate intake (g//000kcal) & 58.50 & 7.16 & 58.71 & 7.30 & 0.789 & 51.39 & 8.31 & 52.73 & 7.68 & 0.128 \\
\hline Vitamin $D$ intake $(\mu \mathrm{g} / 1000 \mathrm{kcal})$ & 7.96 & 5.01 & 7.94 & 4.52 & 0.963 & 8.62 & 5.80 & 7.05 & 5.00 & 0.009 \\
\hline Grip strength/body weight $(\mathrm{kgf} / \mathrm{kg})$ & 0.50 & 0.11 & 0.47 & 0.10 & 0.002 & 0.58 & 0.11 & 0.57 & 0.12 & 0.622 \\
\hline $\begin{array}{l}\text { Calf circumference/body weight } \\
(\mathrm{cm} / \mathrm{kg})\end{array}$ & 0.60 & 0.07 & 0.61 & 0.07 & 0.372 & 0.56 & 0.06 & 0.55 & 0.06 & 0.112 \\
\hline Osteo sono-assessment index & 2.55 & 0.36 & 2.46 & 0.30 & 0.011 & 2.70 & 0.34 & 2.74 & 0.36 & 0.298 \\
\hline Smoking status (n, \%) & & & & & 0.182 & & & & & 0.303 \\
\hline Non-smoker & 172 & 70.5 & 112 & 77.2 & & 59 & 31.7 & 41 & 27.5 & \\
\hline EX-smoker & 50 & 20.5 & 19 & 13.1 & & 73 & 39.2 & 71 & 47.7 & \\
\hline Current smoker & 22 & 9.0 & 14 & 9.7 & & 54 & 29.0 & 37 & 24.8 & \\
\hline Exercise habits (n, \%) & & & & & 0.015 & & & & & 0.153 \\
\hline more than 5 days/week & 98 & 40.2 & 41 & 28.3 & & 64 & 34.4 & 38 & 25.5 & \\
\hline I-4 days/week & 49 & 20.1 & 25 & 17.2 & & 40 & 21.5 & 31 & 20.8 & \\
\hline No exercise & 97 & 39.8 & 79 & 54.5 & & 82 & 44.1 & 80 & 53.7 & \\
\hline Analgesics administration (n, \%) & & & & & 0.183 & & & & & 0.006 \\
\hline No & 232 & 95.1 & 133 & 91.7 & & 184 & 98.9 & 139 & 93.3 & \\
\hline Yes & 12 & 4.9 & 12 & 8.3 & & 2 & 1.1 & 10 & 6.7 & \\
\hline
\end{tabular}

Notes: $p$-values were from the Student's $t$-test for continuous variables and the chi-squared test for categorical variables; $p$-values $<0.05$ are in bold; Non-drinker without $\mathrm{CP}, \mathrm{n}=244$; Non-drinker with $\mathrm{CP}, \mathrm{n}=145$; Drinker without $\mathrm{CP}, \mathrm{n}=186$; Drinker with $\mathrm{CP}, \mathrm{n}=149$.

Abbreviations: BMI, body mass index; CRP, C-reactive protein; $25(\mathrm{OH}) \mathrm{D}$, 25-hydroxyvitamin $\mathrm{D}$; CP, chronic pain; SD, standard deviation.

Table 3 Interaction Between CP and Drinking Habits on Serum 25(OH)D Concentrations and Comparison of Adjusted Serum 25 $(\mathrm{OH}) \mathrm{D}$ Values

\begin{tabular}{|c|c|c|c|c|c|c|c|c|c|c|}
\hline \multirow[t]{2}{*}{ Drinking Habits } & \multirow[t]{2}{*}{ CP Status } & \multirow[t]{2}{*}{ Mean } & \multirow[t]{2}{*}{ SD } & \multirow[t]{2}{*}{ Estimated Mean Difference } & \multicolumn{2}{|l|}{$95 \% \mathrm{Cl}$} & \multirow[t]{2}{*}{ pl } & \multirow[t]{2}{*}{ p2 } & \multirow[t]{2}{*}{ p3 } & \multirow[t]{2}{*}{ p4 } \\
\hline & & & & & Lower & Upper & & & & \\
\hline \multirow[t]{2}{*}{ Non-drinker } & Without & 22.35 & 6.77 & 0.28 & -1.09 & 1.65 & 0.691 & 0.021 & $<0.001$ & 0.098 \\
\hline & With & 21.82 & 6.40 & & & & & & & \\
\hline \multirow[t]{2}{*}{ Drinker } & Without & 27.01 & 9.24 & 2.44 & 0.67 & 4.22 & 0.007 & & & \\
\hline & With & 25.30 & 7.83 & & & & & & & \\
\hline
\end{tabular}

Notes: Analyses were adjusted for sex, age, body mass index, the smoking status, exercise habit, the analgesics administration status, the osteo sono-assessment index, grip strength/body weight, and calf circumference/body weight; $p \mathrm{I}, \mathrm{p}$-value of the one-way analysis of covariance; $p 2, p$-value of main effect of $\mathrm{CP}$ on serum $25(\mathrm{OH}) \mathrm{D}$ concentrations; $p 3, p$-value of main effect of drinking habits on serum 25(OH)D concentrations; $p 4$, $p$-value of interaction test between $\mathrm{CP}$ and drinking habits on serum 25 $(\mathrm{OH}) \mathrm{D}$ concentrations; $p$-values $<0.05$ are in bold; Bonferroni multiple comparisons post hoc test was performed; Non-drinker without $\mathrm{CP}$, $\mathrm{n}=244$; Non-drinker with $\mathrm{CP}$, $\mathrm{n}=145$; Drinker without $\mathrm{CP}, \mathrm{n}=186$; Drinker with $\mathrm{CP}, \mathrm{n}=149$.

Abbreviations: 25(OH)D, 25-hydroxyvitamin D; CP, chronic pain; SD, standard deviation; Cl, confidence interval. 
Table 4 Logistic Analysis of Chronic Pain as a Dependent Variable with Drinking Habits as an Independent Variable

\begin{tabular}{|l|l|l|l|l|l|}
\hline \multirow{2}{*}{} & & \multirow{2}{*}{ OR } & \multicolumn{2}{|l|}{$95 \%$ Cl } & \multirow{2}{*}{-value } \\
\cline { 4 - 5 } & & & Lower & Upper & \\
\hline \multirow{2}{*}{ All } & Model I & 1.427 & 1.004 & 2.028 & $\mathbf{0 . 0 4 8}$ \\
& Model 2 & 1.425 & 0.996 & 2.038 & 0.052 \\
& Model 3 & 1.467 & 1.018 & 2.114 & $\mathbf{0 . 0 4 0}$ \\
\hline
\end{tabular}

Notes: OR indicates the odds ratio of drinking habits for chronic pain; Model I, adjusted for sex, age, and BMI; Model 2, adjusted for sex, age, BMI, the smoking status, and exercise habit; Model 3, adjusted for sex, age, BMI, the smoking status, exercise habit, the analgesics administration status, the osteo sono-assessment index, grip strength/body weight, and calf circumference/body weight; $p$-values < 0.05 are in bold; All, $\mathrm{n}=724$.

Abbreviations: OR, odds ratio; $\mathrm{Cl}$, confidence interval; $\mathrm{BMI}$, body mass index.

Table 5 Logistic Analysis of the Categorized Serum 25(OH)D Levels as a Dependent Variable with Chronic Pain as an Independent Variable

\begin{tabular}{|l|l|l|l|l|l|}
\hline \multirow{2}{*}{} & & \multirow{2}{*}{ OR } & \multicolumn{2}{|l|}{$95 \%$ Cl } & \multirow{2}{*}{ p-value } \\
\cline { 4 - 5 } & & & Lower & Upper & \\
\hline \multirow{2}{*}{ All } & Model I & 0.761 & 0.541 & 1.070 & 0.116 \\
& Model 2 & 0.777 & 0.548 & 1.102 & 0.157 \\
& Model 3 & 0.823 & 0.577 & 1.174 & 0.283 \\
\hline \multirow{2}{*}{ Non-drinker } & Model I & 0.852 & 0.549 & 1.323 & 0.476 \\
& Model 2 & 0.896 & 0.571 & 1.405 & 0.631 \\
& Model 3 & 0.975 & 0.613 & 1.552 & 0.916 \\
\hline \multirow{2}{*}{ Drinker } & Model I & 0.534 & 0.300 & 0.950 & $\mathbf{0 . 0 3 3}$ \\
& Model 2 & 0.502 & 0.275 & 0.915 & $\mathbf{0 . 0 2 4}$ \\
& Model 3 & 0.499 & 0.268 & 0.927 & $\mathbf{0 . 0 2 8}$ \\
\hline
\end{tabular}

Notes: OR indicates the odds ratio of chronic pain for the categorical 25(OH)D levels; Model I, adjusted for sex, age, and BMI; Model 2, adjusted for sex, age, BMI, the smoking status, and exercise habit; Model 3, adjusted for sex, age, BMI, the smoking status, exercise habit, the analgesics administration status, the osteo sonoassessment index, grip strength/body weight, and calf circumference/body weight; $p$-values $<0.05$ are in bold; All, $n=724$; Non-drinker, $n=389$; Drinker, $n=335$. Abbreviations: $\mathrm{OR}$, odds ratio; $\mathrm{Cl}$, confidence interval; 25(OH)D, 25 hydroxyvitamin D; BMI, body mass index.

body weight (odds ratio: $0.499 ; 95 \%$ confidence interval: $0.268-0.927 ; p=0.028$ ), but not in non-drinkers.

\section{Discussion}

This cross-sectional study investigated the association between serum $25(\mathrm{OH}) \mathrm{D}$ concentrations and $\mathrm{CP}$ with stratification by drinking habits. The results obtained showed that drinkers with $\mathrm{CP}$ had lower 25(OH)D concentrations than those without $\mathrm{CP}$. This result implies that lower 25 $(\mathrm{OH}) \mathrm{D}$ concentrations correlated with $\mathrm{CP}$ in drinkers only.

Previous studies reported discordant findings on the relationship between serum 25(OH)D concentrations and CP. Several large cross-sectional studies showed low 25(OH)D concentrations with widespread $\mathrm{CP}^{33,34}$ Furthermore, a systematic review published in 2018 concluded that low $25(\mathrm{OH}) \mathrm{D}$ concentrations may be associated with pain conditions. $^{35}$ On the other hand, large population-based studies found no relationships between $25(\mathrm{OH}) \mathrm{D}$ levels and self-reported CP after adjustments for several confounding factors. ${ }^{14,36}$ The reasons for inconsistencies in the relationship between serum $25(\mathrm{OH}) \mathrm{D}$ concentrations and CP currently remain unknown because these studies did not perform analyses with the stratification of subjects by factors considered to affect the association between $\mathrm{CP}$ and $25(\mathrm{OH}) \mathrm{D}$. To the best of our knowledge, the present study is the first to investigate the association between serum 25(OH)D and CP according to drinking habits, which is assumed to influence this relationship.

The positive effects of moderate alcohol consumption on CP have been demonstrated. ${ }^{37-39}$ However, these findings may be attributed to "reverse causation". "Reverse causation" means that individuals with $\mathrm{CP}$ reduce their alcohol intake because of the harmful effects of alcohol on their symptoms. A Mendelian randomization study using UK Biobank recently showed that alcohol consumption did not have a positive impact on the risk of widespread CP. ${ }^{40}$ In contrast, the present results suggested that drinking habits had negative effects on CP. Previous studies only included individuals with widespread CP. ${ }^{37-40}$ A review published in 2016 reported that the prevalence of widespread CP was $10-15 \%{ }^{41}$ However, $40.6 \%$ of subjects in the present study had CP. Therefore, we may have included not only subjects with widespread CP but also those with another CP status, such as osteoarthritis. Previous cross-sectional and longitudinal studies demonstrated a relationship between moderate alcohol consumption and the development of osteoarthritis. ${ }^{42,43}$ Therefore, the present results appear to support the relationship between alcohol consumption and $\mathrm{CP}$.

Although previous studies investigated the effects of alcohol consumption on serum vitamin D concentrations, this relationship remains unclear. $^{15-22}$ In studies that reported a positive relationship between frequent alcohol consumption and the vitamin D status, alcohol suppressed the secretion of parathyroid hormone, which controls metabolism from $25(\mathrm{OH}) \mathrm{D}$ to $1,25(\mathrm{OH}) 2 \mathrm{D}$ in the kidney. $^{23-25}$ These findings suggested that an increase in unconverted $25(\mathrm{OH}) \mathrm{D}$ may have resulted in higher serum $25(\mathrm{OH}) \mathrm{D}$ concentrations in drinkers. Drinkers had higher $25(\mathrm{OH}) \mathrm{D}$ concentrations than non-drinkers in the present study. Therefore, high serum $25(\mathrm{OH}) \mathrm{D}$ concentrations 
induced by alcohol consumption seems to mean not a favorable status of vitamin $\mathrm{D}$ but rather a deficiency of $1,25(\mathrm{OH}) 2 \mathrm{D}$, which is the active form of vitamin $\mathrm{D}$.

Several studies have reported that vitamin D deficiency causes a decrease in bone density, muscle weakness, and bone sensitivity. ${ }^{44,45}$ Vitamin D deficiency can lead to muscle weakness, which can cause herniated discs, and the other study has shown that vitamin D levels are associated with pain severity in patients with low back pain. ${ }^{46}$ In addition, several studies have demonstrated an association between vitamin D status and serum creatine kinase levels or inflammatory cytokines. ${ }^{47,48}$ Furthermore, the link between vitamin D deficiency and alteration of nociception via changes in gut microbiota has previously been detected in mice. ${ }^{49}$ Therefore, the analgesic effects of vitamin D may be compromised in subjects with drinking habits, owing to alcohol-induced disturbances in the metabolism of $25(\mathrm{OH}) \mathrm{D}$ to $1.25(\mathrm{OH}) 2 \mathrm{D}$. Furthermore, insufficient vitamin $\mathrm{D}$ intake may adversely affect $\mathrm{CP}$ in drinkers. Drinkers with CP had a significantly lower intake of vitamin D than those without $\mathrm{CP}$ in the present study. Therefore, the association found between low 25(OH)D concentrations and the development of CP in drinkers only appears to support our hypothesis that drinking habits affect the inhibitory effects of vitamin $\mathrm{D}$ on pain.

These results indicate the importance of maintaining sufficient serum $25(\mathrm{OH}) \mathrm{D}$ concentrations, particularly in drinkers. Furthermore, vitamin D supplementation appears to be more effective for the treatment of CP in drinkers. However, there are several limitations in the present study that need to be addressed. The causality between serum 25 $(\mathrm{OH}) \mathrm{D}$ concentrations, $\mathrm{CP}$, and drinking habits remains unclear because of the nature of this cross-sectional study. Furthermore, we need to consider the selection bias. In the present study, the percentage of healthconscious individuals may have been high because the health examination was only conducted on voluntary subjects. In addition, because the participation rate in this study was low, this study's findings are limited in their generalizability. Moreover, we did not include information on the mental conditions of subjects, which may have affected $\mathrm{CP}$, because the number of subjects with complete data of these variables was small.

\section{Conclusion}

We herein performed a cross-sectional study on Japanese subjects to assess the association between serum $25(\mathrm{OH}) \mathrm{D}$ concentrations and $\mathrm{CP}$ in drinkers and non-drinkers. An association between $25(\mathrm{OH}) \mathrm{D}$ concentrations and $\mathrm{CP}$ was only observed in drinkers. These results suggest that drinkers need to maintain sufficient serum 25(OH)D concentrations by an adequate vitamin $\mathrm{D}$ intake in order to inhibit CP.

\section{Acknowledgments}

The present study was funded by a Grant-in-Aid for Scientific Research (B) by the Japan Society for the Promotion of Science, number 19H03882. The authors wish to thank all the field workers and laboratory personnel of the Shika Study for their efforts.

\section{Disclosure}

The authors declare no conflicts of interest.

\section{References}

1. Treede RD, Rief W, Barke A, et al. Chronic pain as a symptom or a disease: the IASP classification of chronic pain for the international classification of diseases (ICD-11). Pain. 2019;160(1):19-27. doi:10. 1097/j.pain.0000000000001384

2. Fayaz A, Croft P, Langford RM, Donaldson LJ, Jones GT. Prevalence of chronic pain in the UK: a systematic review and meta-analysis of population studies. BMJ Open. 2016;6(6):e010364. doi:10.1136/ bmjopen-2015-010364

3. Abdulla A, Adams N, Bone M, et al. Guidance on the management of pain in older people. Age Ageing. 2013;42(Suppl 1):i1-57. doi:10. 1093/ageing/afs199

4. Kawai K, Kawai AT, Wollan P, Yawn BP. Adverse impacts of chronic pain on health-related quality of life, work productivity, depression and anxiety in a community-based study. Fam Pract. 2017;34 (6):656-661. doi:10.1093/fampra/cmx034

5. Gaskin DJ, Richard P. The economic costs of pain in the United States. J Pain. 2012;13(8):715-724. doi:10.1016/j.jpain.2012.03.009

6. Wimalawansa SJ. Non-musculoskeletal benefits of vitamin D. J Steroid Biochem Mol Biol. 2018;175:60-81. doi:10.1016/j.jsbmb. 2016.09.016

7. Ross AC, Manson JE, Abrams SA, et al. The 2011 report on dietary reference intakes for calcium and vitamin $\mathrm{D}$ from the institute of medicine: what clinicians need to know. J Clin Endocrinol Metab. 2011;96(1):53-58. doi:10.1210/jc.2010-2704

8. Ghai B, Bansal D, Kanukula R, et al. Vitamin D supplementation in patients with chronic low back pain: an open label, single arm clinical trial. Pain Physician. 2017;20(1):E99-e105. doi:10.36076/ppj.2017.1. E99

9. Lakkireddy M, Karra ML, Patnala C, et al. Efficiency of vitamin D supplementation in patients with mechanical low back ache. J Clin Orthop Trauma. 2019;10(6):1101-1110. doi:10.1016/j.jcot.2019.06.018

10. Schlogl M, Chocano-Bedoya P, Dawson-Hughes B, et al. Effect of monthly vitamin D on chronic pain among community-dwelling seniors: a randomized, double-blind controlled trial. J Am Med Dir Assoc. 2019;20(3):356-361. doi:10.1016/j.jamda.2018.09.004

11. Straube S, Derry S, Straube C, Moore RA. Vitamin D for the treatment of chronic painful conditions in adults. Cochrane Database Syst Rev. 2015;5:Cd007771.

12. McCabe PS, Pye SR, Beth JM, et al. Low vitamin D and the risk of developing chronic widespread pain: results from the European male ageing study. BMC Musculoskelet Disord. 2016;17:32. doi:10.1186/ s12891-016-0881-6 
13. Thorneby A, Nordeman LM, Johanson EH. No association between level of vitamin D and chronic low back pain in Swedish primary care: a cross-sectional case-control study. Scand J Prim Health Care. 2016;34(2):196-204. doi:10.1080/02813432.2016.1183557

14. Wu Z, Camargo CA, Sluyter JD, et al. Association between serum 25-hydroxyvitamin D levels and self-reported chronic pain in older adults: a cross-sectional analysis from the ViDA study. J Steroid Biochem Mol Biol. 2019;188:17-22. doi:10.1016/j.jsbmb.2018.11. 018

15. Larose TL, Chen Y, Camargo CA, Langhammer A, Romundstad P, Mai XM. Factors associated with vitamin D deficiency in a Norwegian population: the HUNT Study. J Epidemiol Community Health. 2014;68(2):165-170. doi:10.1136/jech-2013-202587

16. Gorter EA, Krijnen P, Schipper IB. Vitamin D deficiency in adult fracture patients: prevalence and risk factors. Eur J Trauma Emerg Surg. 2016;42(3):369-378. doi:10.1007/s00068-015-0550-8

17. Sobral-Oliveira MB, Faintuch J, Guarita DR, Oliveira CP, Carrilho FJ. Nutritional profile of asymptomatic alcoholic patients. Arq Gastroenterol. 2011;48(2):112-118.

18. Naude CE, Carey PD, Laubscher R, Fein G, Senekal M. Vitamin $\mathrm{D}$ and calcium status in South African adolescents with alcohol use disorders. Nutrients. 2012;4(8):1076-1094. doi:10.3390/nu40 81076

19. Santori C, Ceccanti M, Diacinti D, et al. Skeletal turnover, bone mineral density, and fractures in male chronic abusers of alcohol. $J$ Endocrinol Invest. 2008;31(4):321-326. doi:10.1007/BF03346365

20. Janssen HC, Emmelot-Vonk MH, Verhaar HJ, van der Schouw YT. Determinants of vitamin D status in healthy men and women aged 40-80 years. Maturitas. 2013;74(1):79-83. doi:10.1016/j.maturitas. 2012.10.008

21. Kühn T, Kaaks R, Teucher B, et al. Dietary, lifestyle, and genetic determinants of vitamin D status: a cross-sectional analysis from the European prospective investigation into cancer and nutrition (EPIC)-Germany study. Eur J Nutr. 2014;53(3):731-741. doi:10.10 07/s00394-013-0577-8

22. Hirani V, Cumming RG, Blyth FM, et al. Vitamin D status among older community dwelling men living in a sunny country and associations with lifestyle factors: the concord health and ageing in men project, Sydney, Australia. J Nutr Health Aging. 2013;17(7):587-593. doi:10.1007/s12603-013-0013-z

23. McCarty MF, Thomas CA. PTH excess may promote weight gain by impeding catecholamine-induced lipolysis-implications for the impact of calcium, vitamin D, and alcohol on body weight. Med Hypotheses. 2003;61(5-6):535-542. doi:10.1016/S0306-9877(03)00 227-5

24. Rapuri PB, Gallagher JC, Balhorn KE, Ryschon KL. Alcohol intake and bone metabolism in elderly women. Am J Clin Nutr. 2000;72 (5):1206-1213. doi:10.1093/ajcn/72.5.1206

25. Sampson HW. Alcohol, osteoporosis, and bone regulating hormones. Alcohol Clin Exp Res. 1997;21(3):400-403. doi:10.1111/j.1530-0277. 1997.tb03782.x

26. Shankar K, Liu X, Singhal R, et al. Chronic ethanol consumption leads to disruption of vitamin D3 homeostasis associated with induction of renal 1,25 dihydroxyvitamin D3-24-hydroxylase (CYP24A1). Endocrinology. 2008;149(4):1748-1756. doi:10.1210/en.2007-0903

27. Zerwekh JE. The measurement of vitamin D: analytical aspects. Ann Clin Biochem. 2004;41(Pt4):272-281. doi:10.1258/0004563041201 464

28. Snellman G, Melhus H, Gedeborg R, et al. Determining vitamin D status: a comparison between commercially available assays. PLoS One. 2010;5(7):e11555. doi:10.1371/journal.pone.0011555

29. Rosen CJ. Vitamin D insufficiency. $N$ Engl J Med. 2011;364 (3):248-254. doi:10.1056/NEJMcp1009570

30. Manson JE, Brannon PM, Rosen CJ, Taylor CL. Vitamin D deficiency - is there really a pandemic? N Engl J Med. 2016;375 (19):1817-1820. doi:10.1056/NEJMp1608005
31. Kobayashi S, Murakami K, Sasaki S, et al. Comparison of relative validity of food group intakes estimated by comprehensive and brief-type self-administered diet history questionnaires against 16 d dietary records in Japanese adults. Public Health Nutr. 2011;14 (7):1200-1211. doi:10.1017/S1368980011000504

32. Sasaki S, Yanagibori R, Amano K. Self-administered diet history questionnaire developed for health education: a relative validation of the test-version by comparison with 3-day diet record in women. J Epidemiol. 1998;8(4):203-215. doi:10.2188/jea.8.203

33. Atherton K, Berry DJ, Parsons T, Macfarlane GJ, Power C, Hypponen E. Vitamin D and chronic widespread pain in a white middle-aged British population: evidence from a cross-sectional population survey. Ann Rheum Dis. 2009;68(6):817-822. doi:10.11 36/ard.2008.090456

34. McBeth J, Pye SR, O'Neill TW, et al. Musculoskeletal pain is associated with very low levels of vitamin D in men: results from the European male ageing study. Ann Rheum Dis. 2010;69(8):14 48-1452. doi:10.1136/ard.2009.116053

35. Wu Z, Malihi Z, Stewart AW, Lawes CM, Scragg R. The association between vitamin $\mathrm{D}$ concentration and pain: a systematic review and meta-analysis. Public Health Nutr. 2018;21(11):2022-2037. doi:10. 1017/S1368980018000551

36. Hirani V, Blyth FM, Naganathan V, et al. Active vitamin D $(1,25$ dihydroxyvitamin D) is associated with chronic pain in older Australian men: the concord health and ageing in men project. J Gerontol a Biol Sci Med Sci. 2015;70(3):387-395. doi:10.1093/ gerona/glu126

37. Beasley MJ, Macfarlane TV, Macfarlane GJ. Is alcohol consumption related to likelihood of reporting chronic widespread pain in people with stable consumption? Results from UK biobank. Pain. 2016;157 (11):2552-2560. doi:10.1097/j.pain.0000000000000675

38. Kim CH, Vincent A, Clauw DJ, et al. Association between alcohol consumption and symptom severity and quality of life in patients with fibromyalgia. Arthritis Res Ther. 2013;15(2):R42. doi:10.1186/ $\operatorname{ar} 4200$

39. Macfarlane GJ, Beasley M. Alcohol consumption in relation to risk and severity of chronic widespread pain: results from a UK population-based study. Arthritis Care Res (Hoboken). 2015;67 (9):1297-1303. doi:10.1002/acr.22604

40. Beasley M, Freidin MB, Basu N, Williams FMK, Macfarlane GJ. What is the effect of alcohol consumption on the risk of chronic widespread pain? A Mendelian randomisation study using UK Biobank. Pain. 2019;160(2):501-507. doi:10.1097/j.pain.0000000000001426

41. Mansfield KE, Sim J, Jordan JL, Jordan KP. A systematic review and meta-analysis of the prevalence of chronic widespread pain in the general population. Pain. 2016;157(1):55-64. doi:10.1097/j.pain.00 00000000000314

42. Haugen IK, Magnusson K, Turkiewicz A, Englund M. The prevalence, incidence, and progression of hand osteoarthritis in relation to body mass index, smoking, and alcohol consumption. J Rheumatol. 2017;44(9):1402-1409. doi:10.3899/jrheum.170026

43. Magnusson K, Mathiessen A, Hammer HB, et al. Smoking and alcohol use are associated with structural and inflammatory hand osteoarthritis features. Scand J Rheumatol. 2017;46(5):388-395. doi:10.1080/03009742.2016.1257736

44. Garg MK, Tandon N, Marwaha RK, Menon AS, Mahalle N. The relationship between serum 25 -hydroxy vitamin $\mathrm{D}$, parathormone and bone mineral density in Indian population. Clin Endocrinol (Oxf). 2014;80(1):41-46. doi:10.1111/cen.12248

45. Cauley JA, Parimi N, Ensrud KE, et al. Serum 25-hydroxyvitamin $\mathrm{D}$ and the risk of hip and nonspine fractures in older men. $J$ Bone Miner Res. 2010;25(3):545-553. doi:10.1359/jbmr.090826

46. Gokcek E, Kaydu A. Assessment of relationship between vitamin D deficiency and pain severity in patients with low back pain: a retrospective, observational study. Anesth Essays Res. 2018;12 (3):680-684. doi:10.4103/aer.AER_96_18 
47. Pennisi M, Di Bartolo G, Malaguarnera G, Bella R, Lanza G, Malaguarnera M. Vitamin D serum levels in patients with statin-induced musculoskeletal pain. Dis Markers. 2019;2019:35 49402. doi: $10.1155 / 2019 / 3549402$

48. Choi M, Park H, Cho S, Lee M. Vitamin D3 supplementation modulates inflammatory responses from the muscle damage induced by high-intensity exercise in SD rats. Cytokine. 2013;63(1):27-35. doi:10.1016/j.cyto.2013.03.018
49. Guida F, Boccella S, Belardo C, et al. Altered gut microbiota and endocannabinoid system tone in vitamin D deficiency-mediated chronic pain. Brain Behav Immun. 2020;85:128-141. doi:10.1016/j. bbi.2019.04.006

\section{Publish your work in this journal}

The Journal of Pain Research is an international, peer reviewed, open access, online journal that welcomes laboratory and clinical findings in the fields of pain research and the prevention and management of pain. Original research, reviews, symposium reports, hypothesis formation and commentaries are all considered for publication. The manuscript management system is completely online and includes a very quick and fair peer-review system, which is all easy to use. Visit http:// www.dovepress.com/testimonials.php to read real quotes from published authors. 